\title{
A study of carbohydrate metabolism in postnecrotic cirrhosis of liver
}

\author{
ROSE T. T. YEUNG AND CHRISTINA C. L. WANG \\ From the University Department of Medicine, Queen Mary Hospital, Hong Kong
}

SUMMARY Intravenous glucose tolerance, insulin tolerance, tolbutamide, and glucagon tests were carried out in 21 patients with postnecrotic cirrhosis. Based arbitrarily on the bromsulphthalein retention they were divided into group $\mathrm{A}$, nine patients with less impaired liver function, and group B, 12 patients with greater impairment of liver function. Intravenous glucose and insulin tolerances were reduced in both groups. The hypoglycaemic effect of tolbutamide was similar in the controls and in both groups of cirrhotic patients but this was achieved at higher plasma insulin levels in group B indicating resistance of the liver to the effect of endogenous insulin. The blood glucose response to glucagon was markedly impaired in group B patients which is consistent with this hypothesis. In contrast to the insulin response to glucose and tolbutamide, the insulin response to glucagon was reduced in the cirrhotic patients. Fasting human growth hormone and free fatty acid levels were elevated in both groups but they were not considered to be important factors in the production of insulin resistance.

It is now widely recognized that the oral glucose tolerance is abnormal in a high proportion of patients with cirrhosis of the liver. Different mechanisms have been considered in its production. It has been postulated (Hernandez, Zorrilla, and Gershberg, 1969) that in cirrhotic subjects insulin secretion was reduced and insulin resistance was increased as a result of elevated growth hormone and fasting free fatty acid (FFA) levels in blood. On the other hand, Berkowitz (1969) concluded that insulin secretion was not deficient but there was a reduced sensitivity to the hypoglycaemic action of endogenous insulin. Increased resistance to the hypoglycaemic effect of exogenous insulin also has been recognized by other workers (Danowki, Gillespie, Fergus, and Puntereri, 1957; Creutzfeldt, Wille, and Kaup, 1962). Megyesi, Samols, and Marks (1967) considered that chronic hepatic disease produced endogenous insulin resistance and hyperinsulinaemia before glucose tolerance became impaired and that diabetes was the result of $\beta$ cell decompensation. They also claimed that the impaired oral and intravenous glucose tolerance in their patients could not have resulted from portosystemic shunting of glucose, impaired hepatic uptake, or elevated fasting FFA levels. Unfortunately,

Received for publication 3 July 1974. with the exception of the last communication, these conclusions were drawn almost exclusively from the results of the oral glucose tolerance test. In addition to the variability in the rate of glucose absorption the oral glucose tolerance test in cirrhotic subjects is affected by the presence of intrahepatic and extrahepatic portosystemic shunting of blood with its content of glucose, insulin, and the intestinal factors which stimulate insulin secretion (McIntyre, Holdsworth, and Turner, 1965). The reports also include a high proportion of subjects with alcoholic cirrhosis in whom commonly there is associated pancreatic pathology.

The present investigations were undertaken to study more closely the relationship between carbohydrate metabolism and insulin secretion in patients with postnecrotic cirrhosis of undetermined origin and to correlate the disorders of carbohydrate metabolism with liver function.

\section{Materials and Methods}

Twenty-one patients with uncomplicated postnecrotic cirrhosis were investigated. All were males and their ages ranged from 23 to 58 (mean $=37.9$ ) years. None had a history of alcoholism. They were arbitrarily divided into two groups according to the results of the bromsulphthalein (BSP) excretion test. 


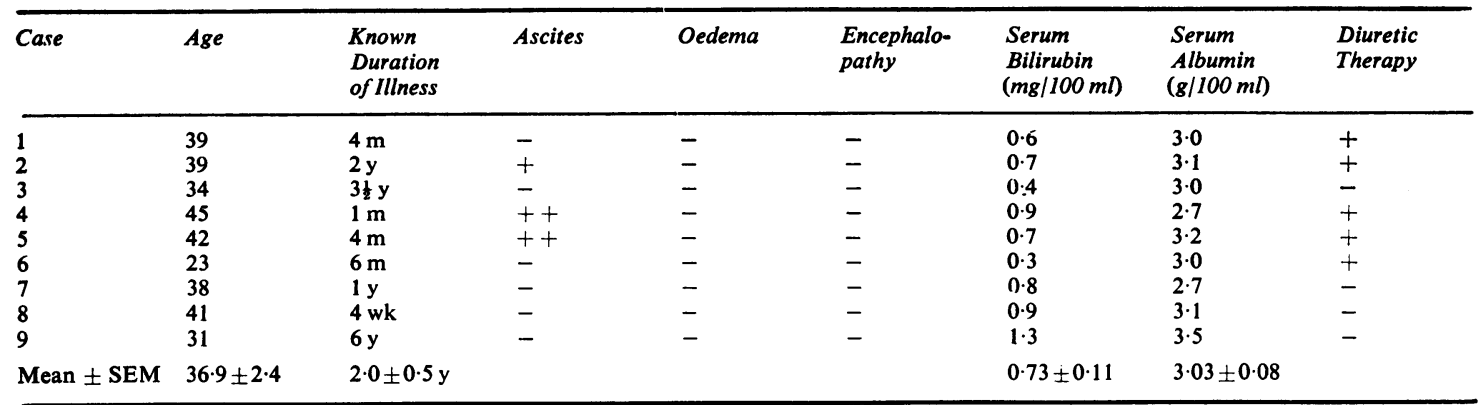

Table I Relevant clinical data and liver function tests in group A patients

\begin{tabular}{|c|c|c|c|c|c|c|c|c|}
\hline Case & Age & $\begin{array}{l}\text { Known } \\
\text { Duration } \\
\text { of Illness }\end{array}$ & Ascites & Oedema & $\begin{array}{l}\text { Encephalo- } \\
\text { pathy }\end{array}$ & $\begin{array}{l}\text { Serum } \\
\text { Bilirubin } \\
(\mathrm{mg} / 100 \mathrm{ml})\end{array}$ & $\begin{array}{l}\text { Serum } \\
\text { Albumin } \\
(\mathrm{g} / 100 \mathrm{ml})\end{array}$ & $\begin{array}{l}\text { Diuretic } \\
\text { Therapy }\end{array}$ \\
\hline $\begin{array}{l}10 \\
11 \\
12 \\
13 \\
14 \\
15 \\
16 \\
17 \\
18 \\
19 \\
20 \\
21\end{array}$ & $\begin{array}{l}37 \\
31 \\
53 \\
35 \\
58 \\
31 \\
27 \\
34 \\
31 \\
40 \\
51 \\
35\end{array}$ & $\begin{array}{l}9 y \\
2 y \\
11 y \\
5 y \\
10 y \\
8 y \\
7 y \\
8 y \\
12 y \\
2 \frac{1}{2} y \\
6 y \\
10 y\end{array}$ & $\begin{array}{l}- \\
- \\
++ \\
+++ \\
+ \\
- \\
- \\
- \\
- \\
- \\
- \\
-\end{array}$ & $\begin{array}{l}- \\
- \\
- \\
+ \\
- \\
- \\
- \\
+ \\
+ \\
+ \\
+ \\
+\end{array}$ & $\begin{array}{l}- \\
- \\
+++ \\
- \\
- \\
++ \\
++ \\
- \\
+++ \\
- \\
- \\
-\end{array}$ & $\begin{array}{l}1.2 \\
0.6 \\
3.5 \\
2.5 \\
1.0 \\
1.0 \\
3.4 \\
08 \\
0.6 \\
1.3 \\
2.0 \\
1.3\end{array}$ & $\begin{array}{l}3.6 \\
2.6 \\
2.5 \\
2.2 \\
2.5 \\
2.3 \\
3 \cdot 1 \\
1.4 \\
1 \cdot 2 \\
1 \cdot 2 \\
2.6 \\
1.9\end{array}$ & $\begin{array}{l}- \\
- \\
+ \\
+ \\
+ \\
+ \\
\dot{t} \\
- \\
- \\
+ \\
- \\
+\end{array}$ \\
\hline Mean \pm SEM & $38.6 \pm 3.0$ & $7 \cdot 5 \pm 1.0 y$ & & & & $1.60 \pm 0.31$ & $2 \cdot 26 \pm 0.22$ & \\
\hline
\end{tabular}

Table II Relevant clinical data and liver function tests in group B patients

Group A, in which BSP retention at 45 min was less than $10 \%$, consisted of nine patients aged 23 to 45 (mean $=36.9$ ) years. The remaining 12 patients, aged 31 to 58 (mean $=38.6$ ) years, had a BSP retention at $45 \mathrm{~min}$ of more than $10 \%$ and were designated group B. The other distinguishing features between the two groups are shown in tables I and II. The diagnosis of postnecrotic cirrhosis was established by aspiration needle biopsy.

All subjects were ensured a carbohydrate intake of 200-300 g daily for three days before the tests which were carried out after fasting overnight. Diuretics were withheld for two weeks before and during the period of investigation.

Ten healthy, non-obese, male subjects aged between 20 and 50 (mean $=35.0)$ years volunteered as controls.

INTRAVENOUS GLUCOSE TOLERANCE TEST The intravenous glucose tolerance test described by Lozner, Winkler, Taylor, and Peters (1941) was employed. Blood glucose was estimated by glucose oxidase (Glucostat, Worthington, Biochemical Cordoration, N.J.) and plasma immunoreactive insulin by the double antibody method of Hales and Randle (1963). The glucose assimilation coefficient, K, was calculated from the formula: $K=\frac{\log _{\mathrm{e}} 2}{t_{\frac{1}{2}}} \times 100$.

The insulin response to intravenous glucose was expressed both as the maximum insulin level which occurred at one or five min after glucose administration and as the area circumscribed by the plasma insulin curve up to 30 minutes. The observed points at fasting, one, five, 15 , and $30 \mathrm{~min}$ were connected by straight lines and the area under these segments measured by planimetry. This area, expressed as $\mathrm{u}$ units $/ \mathrm{ml} \times \min$ (area units), was used as an index of total insulin response for comparison of the relative quantitative changes of insulin secretion during the intravenous glucose tolerance test.

INSULIN TOLERANCE TEST

Soluble insulin, $0 \cdot 1$ unit $/ \mathrm{kg}$, was injected intravenously. Blood glucose was estimated before and five, $15,30,45$, and $60 \mathrm{~min}$ after the injection. Since the nadir in blood glucose response occurs at or before $30 \mathrm{~min}$ in normal subjects and since the later response is more a reflection of the hypoglycaemic 
responsiveness than the insulin sensitivity, the $K$ value in the first 30 min was used as an index of insulin sensitivity. This showed the rate of decline of blood glucose after insulin injection and was calculated in the same way as the $K$ value in the intravenous glucose tolerance test. The minimum blood glucose levels reached during the insulin tolerance test were also compared among the different groups.

\section{TOLBUTAMIDE TEST}

Tolbutamide, $1 \mathrm{~g}$, was injected intravenously. Blood was collected for glucose estimation before and one, five, $15,30,45$, and $60 \mathrm{~min}$ after injection, and plasma for the assay of insulin before and one, five, 15, and 30 min after injection. The blood glucose response was expressed both as the minimum level reached and as the $K$ value calculated in the same way as that of the intravenous glucose tolerance test. The insulin response was expressed as the maximum level and as the total area.

\section{GLUCAGON TEST}

Glucagon, $2 \mathrm{mg}$, was injected intravenously. Blood was collected for glucose estimation before and one, five, $15,30,45$, and $60 \mathrm{~min}$ after injection and plasma for the assay of insulin before and one, five, 15, and $30 \mathrm{~min}$ after injection. Blood glucose response was expressed as the maximum rise and as the increments above the fasting level at various intervals. The insulin response was expressed as the maximum level reached and as the total area.

\section{GROWTH HORMONE AND FREE FATTY ACIDS}

Fasting plasma levels of growth hormone were assayed by the double antibody immunoassay of Schalch and Parker (1964). Fasting plasma levels of FFA were assayed by the titration method of Trout, Estes, and Friedberg (1960).

\section{Results}

It will be seen from tables I and II that the age distribution was similar in the two groups of cirrhotic subjects. The major differences in the clinical

\begin{tabular}{|c|c|c|c|}
\hline & \multirow[t]{2}{*}{ K Value } & \multicolumn{2}{|c|}{ Insulin Response } \\
\hline & & $\begin{array}{l}\text { Maximum } \\
\text { Level } \\
\text { (u units/ml) }\end{array}$ & $\begin{array}{l}\text { Total Area } \\
\text { (u units } / \mathrm{ml} \times \min )\end{array}$ \\
\hline \multirow{2}{*}{$\begin{array}{l}\text { Controls } \\
\text { Cirrhosis } \\
\text { (group A) } \\
\text { (group B) }\end{array}$} & $2.4 \pm 0.3$ & $91 \cdot 7 \pm 8 \cdot 2$ & $1355 \cdot 0 \pm 131 \cdot 7$ \\
\hline & $\begin{array}{l}1 \cdot 5 \pm 0 \cdot 2^{1} \\
1 \cdot 3 \pm 0 \cdot 2^{1}\end{array}$ & $\begin{array}{r}81 \cdot 7 \pm 21 \cdot 6 \\
107 \cdot 1 \pm 18 \cdot 3\end{array}$ & $\begin{array}{l}1286 \cdot 7 \pm 403 \cdot 3 \\
2058 \cdot 3 \pm 361 \cdot 7\end{array}$ \\
\hline
\end{tabular}

Table III Intravenous glucose tolerance test in the controls and two groups of cirrhotic patients (mean $\pm S E M)$

${ }^{1}$ Significant difference from controls.

\begin{tabular}{lll}
\hline & K Value & $\begin{array}{l}\text { Minimum Blood } \\
\text { Glucose Level } \\
(\mathrm{mg} / 100 \mathrm{ml})\end{array}$ \\
\hline Controls & $5 \cdot 4 \pm 0 \cdot 6$ & $23 \cdot 2 \pm 3 \cdot 6$ \\
Cirrhosis (group A) & $3 \cdot 6 \pm 0 \cdot 5^{1}$ & $25 \cdot 7 \pm 4 \cdot 7$ \\
Cirrhosis (group B) & $2 \cdot 8 \pm 0 \cdot 3^{1}$ & $18 \cdot 8 \pm 2 \cdot 6$ \\
\hline
\end{tabular}

Table IV Insulin tolerance test in controls and two groups of cirrhotic patients (mean $\pm S E M$ )

${ }^{1}$ Significant difference from controls.

picture lay in the known duration of symptoms or signs of cirrhosis. Significant differences were also observed in the serum bilirubin and albumin levels. On this basis patients in group A had suffered from cirrhosis for a shorter period and had less impaired liver function than those in group B.

Table III shows the $K$ values and insulin response to the intravenous glucose tolerance test in the controls, and in groups A and B. Both groups of cirrhotic subjects had significantly lower $\mathbf{K}$ values than the controls. The insulin response, though higher in group B, was not possessed of statistical significance.

Table IV presents the results of the insulin tolerance test. The $\mathrm{K}$ values, which reflect the tissue sensitivity to insulin administered intravenously, were significantly lower in both groups of cirrhotic subjects than in the controls. The minimum blood glucose level was reached at or before $30 \mathrm{~min}$ in all

\begin{tabular}{|c|c|c|c|c|}
\hline & \multicolumn{2}{|c|}{ Glucose Response } & \multicolumn{2}{|l|}{ Insulin Response } \\
\hline & K Value & $\begin{array}{l}\text { Minimum Level } \\
(\mathrm{mg} / 100 \mathrm{ml})\end{array}$ & $\begin{array}{l}\text { Maximum Level } \\
\text { (u units } / m l)\end{array}$ & $\begin{array}{l}\text { Total Area } \\
(u \text { units } / m l \times m i n)\end{array}$ \\
\hline $\begin{array}{l}\text { Controls } \\
\text { Cirrhosis (group A) } \\
\text { Cirrhosis (group B) }\end{array}$ & $\begin{array}{l}2 \cdot 2 \pm 0 \cdot 2 \\
2 \cdot 1 \pm 0 \cdot 4 \\
1 \cdot 9 \pm 0 \cdot 4\end{array}$ & $\begin{array}{l}35 \cdot 5 \pm 2 \cdot 8 \\
40 \cdot 4 \pm 5 \cdot 0 \\
31 \cdot 5 \pm 4 \cdot 0\end{array}$ & $\begin{array}{c}85 \cdot 0 \pm 15 \cdot 3 \\
81 \cdot 6 \pm 26 \cdot 9 \\
168 \cdot 0 \pm 22 \cdot 0^{1}\end{array}$ & $\begin{array}{l}1055 \cdot 0 \pm 208 \cdot 3 \\
1206 \cdot 7 \pm 201 \cdot 7 \\
3150 \cdot 0 \pm 470 \cdot 0^{1}\end{array}$ \\
\hline
\end{tabular}

Table V Tolbutamide test in the controls and two groups of cirrhotic patients (mean $\pm S E M$ )

\footnotetext{
${ }^{1}$ Significant difference from controls and group A patients.
} 
controls, in seven out of nine group A patients, and in four out of 12 group B patients. The minimum blood glucose levels of the cirrhotic subjects were not significantly different from those of the controls.

Set out in table $\mathrm{V}$ are the results of the tolbutamide test which reflects the hypoglycaemic effect of endogenous insulin. There was no difference in the fall in blood glucose in response to tolbutamide but the insulin response, expressed both as the maximum plasma insulin level and as the total area was significantly higher in group B on comparison with group $A$ and with the controls.

Table VI and the figure show the results of the glucagon test. The glucose response to glucagon was significantly lower in the cirrhotic patients than in the controls and that in group B was significantly lower than in group $\mathbf{A}$. The insulin response to glucagon was also lower in the cirrhotic patients than in the controls but the difference was only statistically significant on comparing the maximum level in group A with that in the controls.

Table VII gives the fasting levels of blood glucose, plasma insulin, FFA, and human growth hormone. The fasting blood glucose was significantly lower in group B when compared with controls. Fasting plasma insulin levels also were significantly higher in this group when compared with the controls or group A. Fasting plasma FFA and human growth hormone levels were significantly increased in both groups of cirrhotic subjects. But statistical analysis

\begin{tabular}{|c|c|c|c|}
\hline & \multirow{2}{*}{$\begin{array}{l}\text { Glucose Response } \\
\begin{array}{l}\text { Maximum Rise } \\
(\mathrm{mg} / 100 \mathrm{ml})\end{array}\end{array}$} & \multicolumn{2}{|c|}{ Insulin Response } \\
\hline & & $\begin{array}{l}\text { Maximum } \\
\text { Level } \\
\text { (u units } / m l)\end{array}$ & $\begin{array}{l}\text { Total Area } \\
(\text { u units } / m l \times \text { min })\end{array}$ \\
\hline $\begin{array}{l}\text { Controls } \\
\text { Cirrhosis }\end{array}$ & $45 \cdot 1 \pm 5 \cdot 8$ & $91 \cdot 5 \pm 19 \cdot 0$ & $1265 \cdot 0 \pm 361 \cdot 7$ \\
\hline $\begin{array}{l}\text { (group A) } \\
\text { (group B) }\end{array}$ & $\begin{array}{l}32 \cdot 1 \pm 3 \cdot 4^{1} \\
20 \cdot 0 \pm 3 \cdot 1^{2}\end{array}$ & $\begin{array}{l}49 \cdot 1 \pm 8 \cdot 2^{1} \\
60 \cdot 7 \pm 8 \cdot 1\end{array}$ & $\begin{array}{l}636 \cdot 7 \pm 211 \cdot 7 \\
756 \cdot 7 \pm 191 \cdot 7\end{array}$ \\
\hline
\end{tabular}

Table VI Glucagon test in the controls and two groups of cirrhotic patients (mean $\pm S E M$ )

${ }^{2}$ Significant difference from controls.

'Significant difference from controls and group A patients.

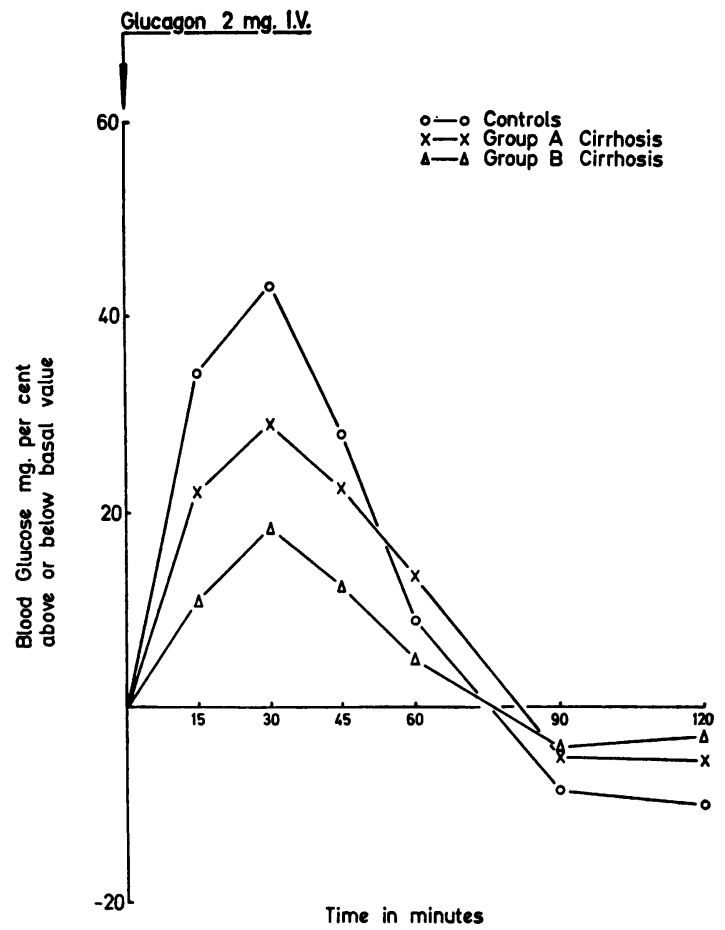

Figure The blood glucose response to glucagon in the controls and both groups of cirrhotic patients (mean).

showed no significant correlation between the plasma human growth hormone or FFA levels with the K values of the intravenous glucose and insulin tolerance tests or the tolbutamide test.

\section{Discussion}

There was probably more advanced cirrhosis in group B than in group A; certainly liver function was more impaired in the former. There is no reliable, sensitive means of assessing the degree of intrahepatic and extrahepatic portosystemic shunting and until such is available it will be impossible to

\begin{tabular}{|c|c|c|c|c|}
\hline & $\begin{array}{l}\text { Glucose } \\
(\mathrm{mg} / 100 \mathrm{ml})\end{array}$ & $\begin{array}{l}\text { Insulin } \\
\text { (u units } / \mathrm{ml})\end{array}$ & $\begin{array}{l}\text { FFA } \\
\text { (m-equiv/l) }\end{array}$ & $\begin{array}{l}\text { Human Growth Hormone } \\
(\mathrm{ng} / \mathrm{ml})\end{array}$ \\
\hline $\begin{array}{l}\text { Controls } \\
\text { Cirrhosis (group A) } \\
\text { Cirrhosis (group B) }\end{array}$ & $\begin{array}{l}73 \cdot 2 \pm 1 \cdot 9 \\
69 \cdot 5 \pm 2 \cdot 3 \\
63 \cdot 8 \pm 1 \cdot 9^{1}\end{array}$ & $\begin{array}{l}18 \cdot 5 \pm 1 \cdot 2 \\
16 \cdot 8 \pm 1 \cdot 6 \\
22 \cdot 1 \pm 1 \cdot 0^{2}\end{array}$ & $\begin{array}{l}251 \cdot 3 \pm 21 \cdot 6 \\
446 \cdot 4 \pm 73 \cdot 3^{1} \\
469 \cdot 7 \pm 75 \cdot 4^{1}\end{array}$ & $\begin{array}{l}1 \cdot 7 \pm 0 \cdot 2 \\
3 \cdot 9 \pm 0 \cdot 7^{1} \\
6 \cdot 6 \pm 1 \cdot 0^{2}\end{array}$ \\
\hline
\end{tabular}

Table VII Fasting levels of blood glucose, plasma insulin, FFA, and human growth hormone in the controls and two groups of cirrhotic patients (mean $\pm S E M$ )

'Significant difference from controls.

'Significant difference from controls and group A patients. 
distinguish between the effect on carbohydrate metabolism of impaired liver function and that of portosystemic shunting.

Both groups of patients had significantly impaired intravenous glucose tolerance tests. Group B subjects had higher plasma insulin levels after intravenous glucose than had group $A$ and the controls. Because of the wide variation within the groups the difference was not statistically significant. The insulin tolerance test showed that both groups of patients were more resistant to the hypoglycaemic effect of intravenously administered insulin, a finding consistent with the existence of insulin resistance. This resistance is even more significant when one considers that plasma insulin reaches a higher level and the hyperinsulinaemia persists longer in the cirrhotic subjects than in the controls after a single intravenous injection of insulin (Devrim, Sencer, Argun, and Alp, 1973). In these respects the results of the present study agree with those previously reported.

Although the rate and the extent of reduction in blood glucose after tolbutamide were the same in the cirrhotic subjects as in the controls, the plasma insulin response was significantly higher in group B. Since insulin secreted in response to tolbutamide normally traverses and acts first on the liver, the development of resistance to endogenous insulin in group B may be related either to the greater diversion of blood away from the liver or to the greater impairment of liver function resulting in reduced deposition of glycogen. The grossly impaired glucose response to glucagon in group B is consistent with this hypothesis if one assumes that glycogenolysis is unimpaired in the presence of cirrhosis.

It has been claimed (Samols and Ryder, 1961) that the liver removes $20-50 \%$ of the insulin passing through it as measured by radioimmunoassay. It might be argued that the more impaired liver function and probably more extensive portosystemic shunting in group B subjects, who were known to have had cirrhosis for a longer period, were responsible for the higher plasma insulin levels during fasting and in response to glucose and tolbutamide. But this argument cannot be applied to the subnormal plasma insulin response to glucagon in both groups of cirrhotic patients. The difference in response may be explained by the different mode of action of the two pharmacological agents. The insulinogenic effect of tolbutamide is independent of the blood glucose level whereas that of glucagon is facilitated by a certain degree of hyperglycaemia. Kasperska, Lawecki, Rogala, and Czyzyk (1971) also noted that glucagon elicited similar insulin responses in controls and cirrhotic subjects.

The low fasting blood glucose and the high fasting plasma insulin levels in group B subjects constitute an anomaly. It has been shown (Olefsky, Farquhar, and Reaven, 1973) that there is a significant inverse correlation between the height of plasma insulin level and the efficiency of glucose uptake in the fasting state in normal and diabetic subjects. This relationship does not hold in the cirrhotic subjects. Whereas the high fasting plasma insulin level may reflect tissue resistance to insulin, the low fasting blood glucose is the consequence of depleted glycogen storage and impaired gluconeogenesis during prolonged fasting. The possibility that an unusually large proportion of the radioimmunoassayable insulin in cirrhotic subjects may be proinsulin has been denied by Gragnoli, Genazzani, Geser, Palazzuoli, Tanganelli, and Felber (1973).

Randle, Garland, Hales, and Newsholme (1963) suggested that elevated levels of plasma FFA might act as insulin antagonists. Mortiaux and Dawson (1961) found that the mean fasting FFA level was raised in 135 of 146 determinations in 131 patients with a variety of liver diseases. On the other hand, Megyesi et al (1967) found similar fasting plasma FFA levels in controls and in cirrhotic patients with normal or impaired glucose tolerance and abnormally high levels in the latter when there was associated clinical diabetes. They were of the opinion that FFAs were not important in the production of insulin resistance in chronic liver disease. The present study shows that fasting plasma FFA levels were significantly elevated in both groups of cirrhotic subjects but further analysis did not show any correlation between the FFA levels and the $K$ values of the intravenous glucose and insulin tolerance tests or the tolbutamide test.

It has been reported that the fasting human growth hormone levels in cirrhosis are elevated and do not fall normally after the oral administration of glucose (Hernandez, Zorrilla, and Gershberg, 1969; Samaan, Stone, and Eckhardt, 1969). On the contrary, a paradoxical rise may be encountered. These findings have been subsequently confirmed. The present study agrees with the finding that fasting plasma human growth hormone levels are elevated in the majority of patients with cirrhosis but shows further that those with the poorest liver function had the highest levels. This possibly may be attributed to the significant hypoalbuminaemia and endogenous hyperoestrogenaemia. However, there was also no correlation between the fasting human growth hormone levels and the $K$ values of the intravenous glucose and insulin tolerance tests and the tolbutamide test. It is, therefore, unlikely that the increased human growth hormone and FFA levels were important factors in the production of insulin resistance in cirrhosis. The impaired glycogenesis 
either as a consequence of impaired liver function and portosystemic shunting or of relative insensitivity of the liver to the effect of insulin can only account for insulin resistance in a proportion of cases. Other factors have yet to be sought.

\section{References}

Berkowitz, D. (1969). Glucose tolerance, free fatty acid, and serum insulin responses in patients with cirrhosis. Amer. J. dig. Dis., 14, 691-699.

Creutzfeldt, W., Wille, K., and Kaup, H. (1962). Intravenöus Belastungen mit Glucose, Insulin und Tolbutamid bei Gesumden, Diabetikern, Leberzirrhotikern und Insulomträgern (Zugierch ein Beitrag zum diagnostichen Wert des Tolbutamid Tests). Dtsch. med. Wschr., 87, 2189-2195.

Danowki, T. S., Gillespie, H. K., Fergus, E. B., and Puntereri, A. J. (1957). Significance of blood sugar and serum electrolyte changes in cirrhosis following glucose, insulin, glucagon or epinephrine. Yale J. Biol. Med., 29, 361-375.

Devrim, S., Sencer, E., Argun, A., and Alp, H. (1973). Mechanism of glucose intolerance with hyperinsulinaemia in liver cirrhosis. Excerpta Medica, International Congress Series No. 280, Abstract 249. Excerpta Medica, Amsterdam.

Gragnoli, G., Genazzani, A. R., Geser, C. A., Palazzuoli, V., Tanganelli, I., and Felber, J. P. (1973). Plasma levels of IRI, HGH, glucagon, 'big'-insulin and blood glucose in cirrhotic patients. Excerpta Medica, International Congress Series No. 280. Abstract 251. Excerpta Medica, Amsterdam.

Hales, C. N., and Randle, P. J. (1963). Immunoassay of insulin with insulin-antibody precipitate. Biochem. J., 88, 137-146.

Hernandez, A., Zorrilla, E., and Gershberg, H. (1969). Decreased insulin production, elevated growth hormone levels and glucose intolerance in liver disease. J. Lab. clin. Med., 73, 25-33.

Kasperska, T., Lawecki, J., Rogala, H., and Czyzyk, A. (1971). The behaviour of insulinaemia in patients with liver cirrhosis after intravenous administration of glucose, tolbutamide and glucagon. Diabetologia, 7, 391-394.

Lozner, E. L., Winkler, A. W., Taylor, F. H. L., and Peters, J. P. (1941). The intravenous glucose tolerance test. J. clin. Invest., 20, 507-515.

McIntyre, N., Holdsworth, C. D., and Turner, D. S. (1965). Intestinal factors in the control of insulin secretion. J. clin. Endocr., 25, 1317-1324.

Megyesi, C., Samols, E., and Marks, V. (1967). Glucose tolerance and diabetes in chronic liver disease. Lancet, 2, 1051-1056.

Mortiaux, A., and Dawson, A. M. (1961). Plasma free fatty acid in liver disease. Gut, 2, 304-309.

Olefsky, J., Farquhar, J. W., and Reaven, G. (1973). Relationship between fasting plasma insulin level and resistance to insulinmediated glucose uptake in normal and diabetic subjects. Diabetes, 22, 507-513.

Randle, P. J., Garland, P. B., Hales, C. N., and Newsholme, E. A. (1963). The glucose fatty-acid cycle: its role in insulin sensitivity and the metabolic disturbances of diabetes mellitus. Lancet, 1 , 785-789.

Samaan, N. A., Stone, D. B., and Eckhardt, R. D. (1969). Serum glucose, insulin and growth hormone in chronic hepatic cirrhosis. Arch. intern. Med., 124, 149-152.

Samols, E., and Ryder, J. A. (1961). Studies on tissue uptake of insulin in man using a differential immunoassay for endogenous and exogenous insulin. J. clin. Invest., 40, 2092-2102.

Schalch, D. S., and Parker, M. L. (1964). A sensitive double antibody immunoassay for human growth hormone in plasma. Nature (Lond.), 203, 1141-1142.

Trout, D. L., Estes, E. H., Jr., and Friedberg, S. J. (1960). Titration of free fatty acids of plasma: a study of current methods and a new modification. J. Lipid Res., 1, 199-202. 